\title{
Sexual Priming, Gender Stereotyping, and Likelihood to Sexually Harass: Examining the Cognitive Effects of Playing a Sexually-Explicit Video Game
}

\author{
Mike Z. Yao $\cdot$ Chad Mahood $\cdot$ Daniel Linz
}

Published online: 22 September 2009

(C) The Author(s) 2009. This article is published with open access at Springerlink.com

\begin{abstract}
The present study examines the short-term cognitive effects of playing a sexually explicit video game with female "objectification" content on male players. Seventy-four male students from a university in California, U.S. participated in a laboratory experiment. They were randomly assigned to play either a sexually-explicit game or one of two control games. Participants' cognitive accessibility to sexual and sexually objectifying thoughts was measured in a lexical decision task. A likelihood-tosexually-harass scale was also administered. Results show that playing a video game with the theme of female "objectification" may prime thoughts related to sex, encourage men to view women as sex objects, and lead to self-reported tendencies to behave inappropriately towards women in social situations.
\end{abstract}

Keywords Media sex · Video game · Priming · Gender stereotype $\cdot$ Sexual harassment $\cdot$ Gender schema . Lexical decision task

\footnotetext{
M. Z. Yao $(\square)$

Department of Media and Communication,

City University of Hong Kong,

Tat Chee Avenue,

Kowloon, Hong Kong

e-mail: mike.yao@cityu.edu.hk

C. Mahood

School of Communication, The Ohio State University,

Columbus, $\mathrm{OH}$, USA

e-mail: mahood.7@osu.edu

D. Linz

Department of Communication, University of California,

Santa Barbara, CA, USA

e-mail: linz@comm.ucsb.edu
}

\section{Introduction}

Video games are one of the most important components of the contemporary entertainment industry. The social and psychological effects of playing video games, particularly those negative effects, have attracted much attention from the general public as well as social scientists in recent years. Much of the public debate about the negative effects of playing video games centers on the violent content typically found in entertainment games. Numerous empirical studies have examined the social and psychological effects associated with playing violent video games (Anderson 2002; Anderson and Bushman 2001; Anderson and Dill 2000; Anderson et al. 2004b; Sherry 2001).

Fewer empirical studies, however, have systematically explored the effects of playing games that are overtly sexual, despite worries about the negative influence of "sexist" or sexually explicit content in video games (Brathwaite 2007; Dill et al. 2008; Dill and Thill 2007). The present study attempts to fill this void by examining the short-term cognitive effects of playing a popular video game containing sexually explicit and female "objectification" content among male players. This laboratory based study addresses this critical gender-related social issue by testing theory that proposes psychological processes that are considered universal and employs a specific research methodology that is less affected by social and cultural factors that may influence study outcomes.

We first review various sexual content typically found in video games. This is followed by a discussion of the effects of exposure to mediated sex. Drawing from several welldeveloped theories within the social cognition frame and previous empirical research specific predictions are then made about the short-term cognitive impacts of playing video games containing sexually-explicit and female "ob- 
jectification" content upon male players. A laboratory experiment is conducted with male undergraduate students from a large U.S. university to test these predictions.

\section{Sexual Content in Video Games}

Controversial sexual content has been a part of video games for nearly as long as the medium has existed (Brathwaite 2007). The 1982 Atari game, Custer's Revenge, caused a public outcry in the U.S. because of its simulation of sex with a captive Native American woman. In this game, players controlled a crudely depicted General George Custer to run from one side of the screen to the other side while dodging flying arrows. The game's objective was to reach the other end of the screen and have sexual intercourse with a naked Native American woman in captivity. More recently, a "minigame" portraying simulated sexual intercourse between the main character and his in-game girlfriend in the globally popular 2004 video game Grand Theft Auto: San Andreas, attracted a great deal of controversy from the public and lawmakers around the world and triggered a series of legal and regulatory actions, and public protests in the United States.

In fact, sexual content of various degrees can be found in electronic games of all types (Brathwaite 2007). In the 1990 s, sexually explicit content was rarely found in family-friendly console games made by Nintendo because the company strictly prohibited such content in their games in 1983 (Sheff 1993), but it was readily available on other game platforms such as PC and Arcade. In 2004 games with explicit sexual imagery and narratives entered the mainstream video game market in the U.S. with the advent of several adult oriented games (e.g., Leisure Suit Larry: Magna Cum Laude, Playboy: the Mansion, the Guy Game, etc.). These were developed and released for popular home console systems (e.g., PlayStation 2, Xbox, etc.) and were widely advertised in mainstream media outlets, and easily available at almost all video game retailers. It is estimated that mature and adult-oriented games containing some type of sexual content account for $12 \%$ of all games released in the U.S. that were rated by the Electronic Software Rating Board (ESRB) (Terdiman 2005).

In a comprehensive review, Brathwaite (2007) described types of sexual content in video games by their function, degree, and purpose. Sexual content in video games may serve different functions. At a basic level sexual content may simply be used for aesthetic purposes. At a more complex level sexual content may also be part of the main mechanics of a video game allowing players to directly control the sex act with virtual characters. Sex can also function as a form of reward. For example, in the popular Leisure Suit Larry video game series, players overcome various obstacles, such as winning poker games, solving puzzles, and answering trivia questions, in order to have sex with various female characters.

Sex in video games may also vary in terms of its degree. Sexual content may range from pure abstraction to extremely explicit depictions. For example, sex acts are merely suggested or assumed in many social simulation games such as The Sims. Teen-oriented games may contain some degree of partial nudity. In games that target adults the amount of sexual content may be significantly more and explicit.

Generally speaking, video games produced in the 21st century are both more interactive and have much better graphics than their predecessors from the $80 \mathrm{~s}$ and $90 \mathrm{~s}$. Instead of performing a series of repetitive moves in prearranged and crudely depicted scenarios, game players can freely interact with intelligent and realistically animated computer avatars. Similarly, the sexual content in these newer video games also became more realistic and complex.

Third, video game sex can be understood in terms of its general purpose. Most obviously, sex depictions are inherently interesting and sex for sex's sake serves the purpose of entertainment. These games also often enable players to explore their sexual fantasies through virtual characters or computer-mediated live partners. Sexualoriented games may also serve the purpose of sex education. For example, The Sex Ed Game, allows parents and teens to play a trivia game together in order to stimulate serious discussions about sexuality in a fun environment. Game developers also use sexual content to convey realism in role-playing or simulation games. In such cases, sexual content would enhance the overall experience of the video game. Recent development in immersive systems and networking technologies even allow users to create their own adult content and simulate sex acts with other human-controlled avatars in realistically rendered virtual environments such as Second Life.

Gender Stereotyping and Sexual Objectification of Females in Video Games

Most video games, whether specifically sexually-oriented or not, often feature hyper-sexualized female characters (Dietz 1998; Dill and Thill 2007; Ray 2004). Female heroines in action-based video games often wear sexy outfits barely covering their bodies. The game character Lara Croft spawned fan sites all over the world, and inspired a wave of sexy female leads in video games (Brathwaite 2007). The October 2004 issue of Playboy magazine featured Luba Licious, a computer generated (CG) female character in the game Leisure Suit Larry, 
Magna Cum Laude, as its centerfold. The magazine also featured nude or seminude images of CG female characters from several other video games.

Most female characters in video games are also stereotyped and objectified. Burgess et al. (2007) analyzed 250 console video game covers and found that female were more likely to be portrayed as ancillary characters, and that over two thirds of the female video game characters (as opposed to only about ten percent of male characters) were represented in stereotyped gender roles (e.g., damsel-indistress and cheerleaders) or the subject of physical objectification. Similar findings were obtained from two recent content analyses of video game magazines (Dill and Thill 2007; Miller and Summers 2007). Dill and Thill (2007) found that female characters in video games were significantly more likely to be portrayed as sexualized, scantily clad, and as showing a mix of sex and aggression than male characters. An important research question naturally following from these content analyses, which guides the present research, is: "What are the effects of playing video games containing such sexually objectified depictions of females?" As a foundation for this research question, we first turn to past literature on the influence of mediated sexual content from traditional media sources.

\section{The Influence of Media Sex in Traditional Media}

Regardless of type, degree, and purpose concern about sexual content in the media, sexist and/or sexually explicit depictions, has generally been about the possible impact they may have on the attitudes and behaviors of male viewers (Gunter 2002; Linz and Malamuth 1993). Zillmann et al. (1981; Zillmann and Sapolsky 1977) proposed the arousal/hedonic valence model to explain how exposure to pornography would lead to aggression through excitation transfer under certain conditions (e.g., being angry), particularly when the sexual content was perceived to be disgusting. Furthermore, Zillmann and Bryant (1982) posited that in the long run, consumption of nonviolent sex materials would lead to a modification of viewer taste in favor of less common sexual depictions (e.g., bondage, sadomasochism, or other "deviant" form of sex) in search for more excitement.

Researchers have also examined the influence of sexual media content on men's attitude towards women. For example, studies have shown that exposure to violent sexual content in which woman appears to be responsible for her own victimization or appears to be sexually aroused can result in changes in men's cognitive appraisal and acceptance of sexual violence (Donnerstein et al. 1987). There also exists a body of empirical evidence to indicate that when men are exposed to sexually explicit material in which women are portrayed as sex objects who are receptive to any sexual advances, they would develop negative attitudes towards women (Gunter 2002; Linz and Malamuth 1993).

Past research on gender portrayals in the media also suggests that gender stereotypical representations of both males and females would influence gender related attitude and perceptions (Scharrer 2005; Ward 2002). Operating from a cultivation effects perspective, which argues that long term and repeated exposure to television can alter viewers' conceptions about social reality (Gerbner et al. 1980), researchers found an apparent correlation between the amount of television viewing and gender-role stereotyping among children and adolescents (Gunter 2002). Empirical evidence also suggested that people are more likely to identify with and learn from attractive media characters performing rewarding activities through a social cognitive process (Bandura 1986, 2001). Based on this view and the fact that mainstream media tend to feature and gratify risky and irresponsible sexual behaviors (Kunkel et al. 1999), researchers propose that young adults would be encouraged to engage in similar promiscuous behaviors as a result of heavy television viewing (Gunter 2002).

Unlike empirical research on sex in traditional media there are only a handful of empirical studies examining the effects of sexual content in video games. In one of the only studies of the effects of sex in videogames (Brenick et al. 2007), 41 male and 46 female were exposed to gender stereotypes and to violence in video games, the results suggest that male who were avid players were more likely to condone negative stereotypes in games that sexually exploited females. In another study (Dill and Thill 2007), participants displayed strong gender stereotyping when asked to describe what the typical male and female character looked like; the single most often stated characteristic for females was "big boobs".

While these studies suggest that playing video games in general may influence sexual and gender related perceptions and attitudes among male players, very little research has been conducted to test the effects of exposure to overtly sexual content in video games. To fill this void, the present study draws on three well-developed theoretical perspectives within the general learning model (the GLM) and the social cognition frame to investigate the short-term cognitive effects, as well as changes in selfreported behavioral tendencies, as a result of playing a sexually-explicit video game with themes of female objectification.

\section{The General Learning Model}

The general learning model was developed in an attempt to merge elements from several existing theoretical perspec- 
tives within in the social cognition frame. The key theoretical perspectives in the GLM include the cognitiveneoassociationistic model (Anderson and Bower 1973), the social-cognitive information processing theory (Huesmann 1998), and social cognitive theory (Bandura 2002) (see Buckley and Anderson 2006, for a complete review). The original incarnation of this model (The General Aggression Model, a.k.a. GAM) dealt exclusively with the effects of violent content on aggression (Anderson and Bushman 2002). However, it was argued recently (Buckley and Anderson 2006) that the model is "general" enough to be applied to all types of media content, including sexuallyexplicit material.

In its most basic form, the GLM proposes that variables related to the person interact with variables related to a given situation to influence one's internal state. Changes in internal state are then associated with changes in subsequent appraisals, decisions, and behaviors (Buckley and Anderson 2006). In the present research we rely on the GLM and its sub-theories to examine the influence of playing sexually-explicit video games with female "objectification" content (a situation variable) among male players (a person variable) on their short-term cognitions (an internal state variable).

The Cognitive-neoassociationistic Model and the Activation of Sex-related Thoughts

The cognitive-neoassociationistic model is based on the perspective that human thoughts and emotions exist as a series of interconnected nodes in a cognitive network (Anderson and Bower 1973). Nodes related to a given concept (e.g., sexual thoughts) that exist in great numbers and are strongly interlinked with each other are the most easily accessed (Jo and Berkowitz 1994). These strongly interconnected nodes are known as knowledge structures (Potter 1999). Media psychology researchers have theorized that exposure to media content can "prime," or activate, these knowledge structures (Roskos-Ewoldsen et al. 2002). Once primed, these knowledge structures are more likely to be accessed in subsequent situations. For example, exposure to sexual media content will prime knowledge structures related to sex. These highly accessible knowledge structures will then be easily accessed in any situation immediately following the exposure to the sexual media content.

In addition to basic priming, the activation of knowledge structures also relies upon the notion of spreading activation. When a particular concept is activated, excitation spreads along the pathways linking it to the connected concepts (Collins and Loftus 1975). If sufficient excitation accumulates, these interlinked concepts are activated as well. Empirical research has found consistent support for the idea that the activation of one thought may spread to other related thoughts and feelings (Berkowitz 1993; Graham and Hudley 1994).

There has been some empirical support for the cognitiveneoassociationistic model and the GLM in the area of video game violence. For example, a recent meta-analysis (Anderson et al., Anderson et al.2004a) found that increases in video game violence could be linked with increases in aggressive cognition, affect, arousal, and behavior. The findings related to aggressive cognitions are of particular interest. These findings are perhaps best illustrated by examining one example of the studies used in the metaanalysis. For instance, Anderson and Dill (2000) found that participants who had played a violent game had greater accessibility to aggressive thoughts (as measured by a reaction-time test) than did those that had played a nonviolent game.

As described above, sexually-oriented video games often contain graphic depictions of sexual imagery and situations (Brathwaite, 2007). Playing these sexuallycharged video games is likely to prime those knowledge structures in the cognitive network that are related to sex. Thus an important potential consequence of playing sexually-explicit video games is the activation of sexually-oriented thoughts. As an application of the GLM, it can be hypothesized that for males (a person variable) exposure to a sexually-explicit video game (a situation variable) will lead to an increased number of sexually-oriented thoughts (an internal state variable). More specifically:

$\mathrm{H} 1$ :

Male players of a sexually-explicit video game will have faster access to sex-related thoughts in their knowledge structure than male players of other types of video games.

\section{Social-cognitive Information Processing Theory} and Gender Stereotyping

As was mentioned above, one of the theoretical perspectives included in the GLM is social-cognitive information processing theory (a.k.a., SIP, Huesmann 1998). Huesmann's theory further explores the concept of a knowledge structure discussed earlier. The theory focuses two forms of knowledge structures, schemata and scripts. According to Huesmann (1998), a schema represents all of an individual's cognitive knowledge related to a given concept (e.g., sex). A script is a well-rehearsed series of linked schemata that represent specific events and actions (e.g., a romantic date, which may or may not include references to a sex schema). According to SIP theory, individuals acquire social information by assigning new information to existing schemata and scripts through a process of comparison to available 
schematic prototypes (Wicks 1992). In other words, when exposed to new information people have a tendency to view it through the lens of existing schemata.

An important implication of SIP theory is its predictive utility in relation to stereotypes and social categorization (Manis et al. 1986). Research has demonstrated that categorization is the means by which a stereotype or a schema is accessed and used to draw an inference or form an impression about a target stimulus (Zarate and Smith 1990). Specifically, when we first meet a person, we would observe a few visible attributes such as gender, skin color, clothing, etc. These attributes would likely be linked to a mental schema about a social group that shares similar characteristics. We then make an initial impression or judgment about this person based on the nature and content of this schema.

Fiske and Taylor (1991) argue that the abstract information stored in a schema about a certain concept is hierarchically organized. Consistent with this view, empirical research on gender stereotyping has found that a perceiver would first classify a woman based on her gender and then assign her to subcategories such as a career woman, a nurturer, or a sex object (Clifton et al. 1976; Deaux et al. 1985). Such classifications will influence people's subsequent behavior toward the target person.

Previous research suggests that media is a significant source of influence in the development and accessibility of cognitive schemata (Potter 1999; Shrum 2002; Wicks 1992). Specifically related to media and gender stereotyping, it has been found that male subjects exposed to sexually objectified depictions of women in the media were more likely to think of women as sex objects, and were more likely to engage in inappropriate sexual advances in a subsequent interaction with a female (Mulac et al. 2002; Rudman and Borgida 1995). Dill et al (2008) tested the effects of exposure to sex-typed video game characters versus images of professional men and women on judgments and attitudes supporting aggression against women. Results showed experimental effects of short-term exposure to stereotypical media content on sexual harassment judgments.

Some have claimed that video games in general are designed by males for other males and tend to feed into masculine fantasies of control, power and destruction (Provenzo 1991). This theme of male fantasies is particularly pronounced in sexually-charge video games. For example, in Playboy: the Mansion, the first game built around the Playboy license, the game player becomes Hugh Hefner, and tries to build a virtual Playboy empire by recruiting playmates and publishing sexually-oriented magazines. In this game, the player attempts to convince animated characters to become naked so that the game player may photograph them. Another sexually-charged video game, Leisure Suit Larry: Magna Cum Laude, combines humor and sex. The general plot of this game is quite simple: the main character, a short and nerdy "loser", tries to have sex with as many girls as he can in a college setting. Females in these games are treated as sex objects quite literally both in terms of the narrative and imagery.

Based on the principles of SIP theory, a potential consequence of playing video games that explicitly portray women as sex objects may be an increased accessibility to a specific gender schema of women as sex objects. Rudman and Borgida (1995) found that "women as nurturers" and "women as sex objects" are stored as two contradictory gender sub-schemas under the same higher-order category of women; when one sub-schema is primed (e.g., mother) the accessibility of the other sub-schema (e.g., whore) is suppressed. Further, this schema suppression can be viewed through the process of the General Learning Model. It can be hypothesized that for males (a person variable) exposure to a video game that depicts females as sex objects (a situation variable) will activate more gender-stereotyped cognitions (an internal state variable). More specifically:

$\mathrm{H} 2$ :

Male players of a sexually-explicit video game with themes of sexual-objectification will have faster access to thoughts of women as sex objects than male players of other games.

\section{Behavioral Consequences}

Discussion has thus far focused primarily on the effects of sexually-explicit content on an individual's short-term cognitions. However, a potentially more important concern is the behavioral consequences of playing sexually explicit video games. Recall that, in addition to cognitive effects, the GLM also predicts that exposure to media content, including sexually-explicit content, can affect behavior. A few studies have supported this claim.

Rudman and Borgida (1995), for example, found that male subjects primed with TV ads portraying women as sex objects displayed stereotyped information acquisition and engaged in sexualized behavior during a staged interview of a female confederate (e.g., looking at a confederate's body, sexually motivated, appearing sexist, and likelihood to sexually harass). Mulac (2002) found that men who viewed a degrading sexual film, as compared to those men who viewed a non-degrading sexual film, displayed less anxiety and more dominance when interacting with a female confederate in a subsequent task. McKenzie-Mohr and Zanna (1990) found that gender-schematic male subjects who watched non-violent pornography are significantly more motivated to make sexual advancements toward females than other subjects. Based on these findings from past research, the present study argues that a stimulus that 
primes a perceiver to categorize women negatively in a sexual context may lead to sexist behavioral tendencies toward women.

Additionally, not only exposure to sexist content in video games may lead to sexist behavior, the interactive nature of video games may also contribute to this effect. With regard to video game violence, researchers argue that game play may create an experience that is inherently more violent than viewing violence on television (Malamuth et al. 2005). Unlike viewing television, video games often force the player to engage in constant and repetitive violence. In addition, the television experience is passive, but the video game experience is interactive and experiential, which may then lead to greater effects upon the players. A similar argument can be made for sexuallyoriented games.

Tests of social cognitive theory (Bandura 2002), another key component of the GLM have found that exposure to media portrayals that are positively reinforced or rewarded tend to lead to an increase in imitative behavior. This pattern of effects is especially likely when identification with the rewarded characters is high. Unlike viewers of television programs who simply watch other characters performing sexually-related behaviors, players of video games actually step into the role of the characters by virtually practicing these acts (i.e., strong identification). In addition, sexually oriented video games often directly offer rewards for sex (e.g., giving points for having sex with female characters) or use sex as a reward (e.g., showing sexual imageries after completing a designated task).

Based on the theoretical argument and research findings outlined above, it can be predicted that for males (a person variable) exposure to a video game that depicts females as sex objects (a situation variable) will be more susceptible to inappropriate sexual advances towards women. Specifically,

H3:

Male players of a sexually oriented video game with themes of female "objectification" will be more likely to engage in the self-reported tendency to sexually harass than male participants of other games.

To summarize, the present study draws from the cognitive-neoassociationistic model, the social information processing theory, and the social cognitive theory within the general framework of the general learning model to investigate the short-term cognitive impacts of playing a sexually-explicit video game with themes of female "objectification" among male players. We expect that male participants who played this game will have an increased accessibility to sex-related thoughts and a specific gender schema of women as sex objects. We also predict that they will be more susceptible to engage in inappropriate sexual advances in various social situations.

\section{Method}

Seventy-four male participants between the age of 18 and $47\left(M_{\text {age }}=20.79, S D=3.55\right)$ from a university in California participated in this study. They were randomly assigned to play either a sexually-explicit video game with female "objectification" content $(N=24)$, a control game with nonsexual social interactions $(N=25)$, or a second non-sexual and non-social control game $(\mathrm{N}=25)$ on a Sony PlayStation $2^{\circledR}$ (PS2) game console for 25 minutes. A check of the randomization confirmed that participants in each condition had similar age $\left(F_{(2,74)}=1.516, p=.226\right)$ and video game playing experience $\left(F_{(2,74)}=.872, p=.423\right)$. After game play, they performed a lexical decision task and completed the Likelihood to Sexually Harass (LSH) scale (Pryor 1987; Rudman and Borgida 1995). The lexical decision task included sexual words and neutral words to measure the accessibility of sex-related thoughts. This task also included sexually objectifying and neutral descriptions of women. All words used in this study were scrambled into meaningless letter strings to control for lengths of each word. The LSH scale was used to measure a participant's self-report behavioral tendency (i.e., susceptibility) to sexually harass.

\section{Stimulus Materials}

The sexually oriented game used in this study was Leisure Suit Larry: Magna cum Laude ${ }^{\mathrm{TM}}$ (Leisure Suit Larry). This game is rated "M" for "mature" by the Electronic Software Rating Board (ESRB). In this game, players assume the identity of Larry, a funny-looking and sociallyawkward college student who tries to enter a televised dating show. To achieve this goal, Larry must gain affection from various female characters. Players would explore 17 different locations on and around a college campus to interact with these female characters. Such interactions include playing mini-games (e.g., drinking games, trampoline, and wet T-shirt contests) and engaging in humorous and sexually-suggestive conversations. In addition to its sexually-charged narrative and game objective, Leisure Suit Larry also contains computeranimated nudity as well as photographs of human female models dressed in sexy outfits.

As part of the introduction and training sequence, the beginning of Leisure Suit Larry requires players to go through a series of relatively simple tasks such as navigating the campus, flirting with a female character, and trying to impress her with cocktail mixing and dancing skills. After successfully getting her drunk enough, Larry would have an opportunity to invite her back to his dorm room. This introduction and training sequence would take about 15 to 30 minutes to complete. 
In order to provide adequate control for both the sexual content and the simulated social interactions in Leisure Suit Larry, two control conditions were included in the present study.

The first control game employed was the PS2 version of the Sims. Sims is one of the most popular game series developed for the PC platform. It is a simulation game in which players can freely engage in normal daily activities such as finding a job, earning money, reading books, playing pool, etc. Similar to Leisure Suit Larry, The Sims II allows for social interactions among computer-generated characters, it does not contain any explicit sexual imagery or sexually charged narrative. It is rated "T" for "Teen" by ESRB. Although the PC version of the Sims II is quite different from Leisure Suit Larry, a number of key modifications were made specifically for the PS2 version of this game, making it a suitable control in the present study. First, the animated characters in this game are similar to those found in Leisure Suit Larry. Second, the control of the character in this game was modified to better suit the PS2 controller that is also used to play Leisure Suit Larry. Third, when the players first start to play the PS2 version of the Sims II, they only have access the limited "get a life" single-player mode. This mode serves as a tutorial and offers a fairly challenging set of seven different missions that will take several hours to complete. In this mode, the players are required to complete several goals, such as making new friends or improving a player's home. However, they are prevented from completing more interesting objectives such as winning the affection of female characters or getting married because they are restricted by the fact that they have to spend a great deal of time performing mandatory activities like going to work or refilling its motives. This modification effectively reduced the likelihood of participants engaging in sexually motivated activities (e.g., seeking a mate) and making it a suitable control in our study.

A second control game, PacMan II, was used in the present study. This game served as a true control for the sexual condition because this game does not have any human character, social interaction, or sexual imagery. Players of the PacMan II game simply control a circularshaped smiley-face that eats various objects (e.g., white dots, fruits, coins, etc.) in two-dimensional mazes while being chased by enemies.

\section{The Lexical Decision Task}

The lexical decision task (Meyer and Schvaneveldt 1971; 1976) is widely used in cognitive psychology experimentations as a measure of semantic memory structure or the organization of general world knowledge. This technique has also been used in studies that examine sex-related cognitive structures (Geer and Bellard 1996; Geer and Melton 1997; Spiering et al. 2002). In a typical lexical decision task, participants are presented with a mixture of words and nonwords. Participants are asked to determine as quickly as possible whether a letter string is or is not a word by pressing a button.

In the present study, two groups of lexical decision stimuli were administered; each group contains two sets of words .The first group of stimuli was designed to compare participants' reaction time to either sexual words or neutral words. The second group of lexical decision stimuli included words that described women either as sex objects or non-objectifying descriptions of women. Each word used in the study was scrambled to create a pseduword of equal length. The purpose of scrambling each word used in the study rather than using random letter strings is to ensure that the length and letter combination of each nonword is consistent with the target word.

Sexual and neutral words. Sixteen sexual words (e.g., sex, penis, etc.) and 16 neutral words (e.g., door, bank, etc.) frequently used in past research on sexual priming (Geer and Bellard 1996; Geer and Melton 1997; Spiering et al. 2002) were selected to be the lexical decision stimuli. These words are frequently used in colloquial English and have similar number of letters and syllables.

Sexually objectifying and neutral descriptions of females. In a pilot study, 34 male and 48 female students enrolled in an upper division communication course generated a list of sexually objectifying or neutral words describing women. Participants were asked to free-associate for 90 seconds to the two counterbalanced categories. Words independently generated by more than $33 \%$ of the sample were chosen as examples of that category (Gilbert and Hixon 1991; Rudman and Borgida 1995). Overall, 10 sexually objectifying references of females (e.g. slut, whore, bitch, etc.) and 10 neutral descriptions (e.g. sister, nurturer, caregiver, niece, etc.) were selected to represent each category. Words in each category had similar number of letters and number of syllables. They are also scrambled into meaningless letter strings to be used as control.

The final version of lexical decision task included 104 letter strings divided into eight types of stimuli: 16 words with sexual connotation, 16 non-sexual words, 10 sexuallyobjectifying descriptions of women, 10 neutral (i.e., nonsexual and non-objectifying) references to females, and a corresponding number of scrambled nonwords for each of these categories.

\section{Likelihood to Sexually Harass (LSH) Scale}

The Likelihood to Sexually Harass (LSH) scale (Pryor 1987) contains 10 scenarios depicting sexually-exploitive opportunities (e.g., granting the female subordinate's 
request in exchange for a sexual favor). Respondents were asked to indicate on a 7-point scale (1 being not at all likely and 7 being extremely likely) whether they would take advantage of the depicted situation and sexually exploit the female described in each vignette. There were a total of 29 possible responses to 10 different scenarios. A summation of scores from the 10 scenarios was calculated with a possible total score range from 29 to 203 to measure participants' self-reported tendency to sexually harass. The higher the score, the more likely an individual is to engage in sexually-exploitive behavior in these situations. A check of data revealed no missing scores. The internal reliability of 10 -items LSH was high (Cronbach $\alpha=.927$ ). This is consistent with previous research (Pryor and Meyers 2000). The mean score of the LSH is 93.48, $S D=26.07$. The distribution did not significantly deviate from normal (Skewness $=.684, S E=.274$, Kurtosis $=.233, S E=.541$ ).

\section{Procedure}

Upon arrival to the lab, participants first completed a questionnaire containing general demographic items. They were then led to one of the three small cubicles each equipped with a computer, a TV monitor and a Sony Playstation 2 game console. Based on the outcome of random assignment (drawing a number from a box), participants played Leisure Suit Larry $(n=24)$, the Sims II $(n=25)$, or PacMan II $(n=$ 25 ) for 25 minutes. Prior to game playing, participants were given a brief instruction on how to use the controller. Instructions of the game and a diagram of the control pad were also posted on the walls in each cubicle.

After 25 minutes, participants were instructed to stop playing the game and turn on the computer monitor on a nearby desk in the same cubicle to complete the lexical decision task. The lexical decision task was conducted through the SuperLab Pro ${ }^{\circledR}$ experimentation program. The participants first went through a computerized instruction of the task and 10 practice trials of using words that are unrelated to the present study (e.g., colors). Then the experimenter left the cubicle while the participants completed 104 experimental trials. Each trial consists of a randomly-selected letter string appearing in the middle of the computer screen. The task is to quickly and accurately identify the string as a word or a non-word by pressing predetermined keys. The computer measured accuracy of response and participants' reaction times to the nearest millisecond.

After completing the lexical decision task, the experimenter returned to the cubicle and loaded the computerbased LSH questionnaire administered using SuperLab Pro ${ }^{\circledR}$. Participants were instructed to answer these questions truthfully. Upon completing the LSH scale, participants were debriefed and thanked before they left the lab.
Error Responses and Data Preparation

Several steps were taken to ensure data accuracy. First, we checked whether the error responses in lexical decision tasks (i.e., recognizing a scrambled words as meaningful or vice-versa) were distributed randomly and equally across the conditions. Participant made an average of 7.24 errors out of the 104 trials $(S D=7.51)$. There was no significant difference in the error responses for different word types. Next, a series Kruskal-Wallis non-parametric test of median differences revealed no significant differences in error responses between the three experimental groups across all word type ( $p$ values of the Chi-squared statistics ranged from .20 to .928 ). Given the relatively low error response rate and the fact that the error response were randomly and equally distributed across word types and the three conditions, the error trials were kept in the overall reaction time calculation.

To conduct the reaction time analyses, harmonic means were calculated for each set of words and nonwords (neutral, sexual, sexually objectifying, etc.). A harmonic mean is more desirable than an algebraic mean (i.e., simple average) in reaction time analyses because it takes the skewed nature of reaction time data into consideration while gives the hypothesis testing more power (Ratcliff 1993).

\section{Results}

In this study we predicted that playing a sexually explicit video game with female "objectification" content would increase the accessibility of sex-related thoughts and a "female as sex object" schema. Eight types of words and nonwords in a lexical decision task were used to test these predictions. We expected that players of Leisure Suit Larry, the sexually explicit game, would have faster reaction time when recognizing sexual words and sexually objectifying descriptions of women than other types of words and nonwords of equal lengths, as compared to players of the two control games. A bivariate correlation analysis suggest that participants' harmonic mean reaction times to the eight different word groups were significantly correlated (Pearson Correlation ranges from .464 to .801), A threefactor one-way multivariable analysis of variance (MANOVA), with the three game conditions as the independent variable and average harmonic mean reaction times to the eight word groups as dependent variables, was performed to test our hypotheses. This test revealed a significant multivariate effect for game condition (Wilk's Lambda=.428, $\left.F_{(16,128)}=4.23, p<.000\right)$. To further examine the hypotheses, the between-subject effects were examined. Table 1 displays the results of these comparisons. 
As can be seen from Table 1, male players of Leisure Suit Larry reacted significantly faster $\left(F_{(2 .}{ }_{74}\right)=9.818$, $\left.p<.001, \eta^{2}=.217\right)$ to sexual words $(M$ reaction time $=$ $561.75 \mathrm{~ms}, S D=52.99)$ than players of the Sims II $(M$ reaction time $=663.29 \mathrm{~ms}, S D=93.78)$ and Pac Man II $(M$ reaction time $=645.98 \mathrm{~ms}, S D=100.76)$. However, no significant difference was found between players of the three games for non-sexual words and the corresponding non-word controls. Hypothesis One is, therefore, supported.

Our second hypothesis predicted that players of sexuallyexplicit video game in so far as it portrayed women as sex objects would be primed with thought about women as sex objects. A test of between-subject effects show that male players of Leisure Suit Larry responded significantly faster $\left(F_{(2.74)}=8.852, p<.001, \eta^{2}=.200\right)$ to sexually-objectifying descriptions of women $(M$ reaction time $=571.42 \mathrm{~ms}$, $S D=70.99)$ than male players of the Sims II $\left(M_{\text {reaction }}\right.$ time $\left.=655.56 \mathrm{~ms}, S D=70.46\right)$ and PacMan $I I$ $\left(M_{\text {reaction }}\right.$ time $\left.=651.39 \mathrm{~ms}, S D=92.12\right)$. No significant difference was found for non-objectifying descriptions of female and the corresponding non-word controls. This finding lends support to Hypothesis Two.

Hypothesis Three predicted that individuals who played a sexually-charged video game with female characters as sex objects would display an increased self-reported tendency to sexually harass. A simple one-way ANOVA of participants' LSH scores revealed a significant effect $F_{(2 .}{ }_{74)}=5.97, p<.01, \eta^{2}=.126$. Specifically, players of Leisure Suit Larry reported a significantly greater tendency to sexually harass $(M=105.37, S D=20.25)$ than did players of the Sims $(\Delta M=22.50, p<.01)$ and PacMan II $(\Delta M=$ $14.30, p<.05)$. Hypothesis Three is, therefore, supported.

\section{Discussion}

The primary goal of this study was to investigate the tendency for sexual thoughts, increased accessibility of negative female stereotypes, and a self-reported behavioral tendency to engage in sexual harassment as a result of playing a sexually-oriented video game portraying women as sex objects. The results revealed that, as predicted, playing sexually-oriented video games significantly decreased male participants' reaction time responding to sexual words and sexually objectifying words pertaining to women, as compared to neutral words and non-words and those participants in control conditions (Fig. 1). This is clear evidence that playing a sexually-oriented video game primes sex-related thoughts and increases accessibility to a negative gender schema of females as sex objects. This finding provides empirical support for the cognitive neoassociationistic perspective (Anderson and Bower 1973) and social information processing theory (Huesmann 1998) within the general framework of the general learning theory (Anderson and Bushman 2002).

More importantly, the present study found that playing a sexually-charged video game for merely 25 minutes might increase a self-reported tendency to engage in inappropriate sexual advances. This finding is particularly strong considering the potential for participants to wish give sociallydesirable responses. This finding is in line with previous research on nonviolent pornography that exposure to such content may foster a negative view of females and increase the likelihood of inappropriate sexual exploitations among males (McKnzie-Mohr and Zana 1990; Mulac et al. 2002) and the social cognitive theory of media effects (Bandura 2001). It also suggests that future research should further probe the actual behavioral consequences of playing sexually-oriented video games.

It should be noted that this study is not without its limitations. First, the present study focused primarily on immediate cognitive effects of playing sexually-oriented games. Future research should examine long-term effects. In addition, a typical video game may take hundreds of hours of playing time to complete. The effects of repeated experience on players' cognition, emotion, attitude, and behavior should also be addressed.

Although the sexually-oriented video game chosen in the present research was a popular game title purchased by millions of game player, the use of a single game as treatment may have limited the generalizability of our findings. We cannot be sure if our findings can be extended to all sexually oriented video games. As discussed in the introduction, sexual content in video games may vary in degrees, representation, purpose, and function. Other factors such as humor and violence may also moderate the effects of sexual content. Furthermore, most existing media effects theories tend to focus on the influence of specific types of content (e.g., violence, sex, health, etc.); an implicit assumption in these theories is that the viewers will be exposed to the same content. However, the increasingly interactive video gaming experience would allow different players to see different content even when playing the same game. To what extent can these theories be applied to the video game effects research? Many interesting and important research questions are be addressed in future research. Nevertheless, our predictions about the effects of playing video games in which female characters were quite literally treated as sex objects were based on previous research findings and strong theoretical reasoning. We are confident that the results from this study would be applicable to games with similar content.

While the Likelihood to Sexually Harass Scale (Pryor 1987) has been used and validated extensively in previous research (cf. Pryor and Meyer 2000), and has been found to be correlated with real behaviors (Dall'Ara and Maass 
Table 1 Test of between-subject effects of average harmonic mean lexical decision latency (in milliseconds) by word type and game condition.

\begin{tabular}{|c|c|c|c|c|c|c|c|c|}
\hline \multirow[t]{2}{*}{ Word Type } & \multicolumn{2}{|l|}{$\mathrm{LSL}^{1}$} & \multicolumn{2}{|c|}{ The Sims II } & \multicolumn{2}{|c|}{ PacMan II } & \multirow[t]{2}{*}{$\mathrm{F}(2,74)$} & \multirow[t]{2}{*}{$\eta^{2}$} \\
\hline & Mean & SD & Mean & SD & Mean & $\mathrm{SD}$ & & \\
\hline Sexual words & 561.75 & 52.99 & 663.29 & 93.78 & 645.98 & 100.76 & $9.818^{* * *}$ & .217 \\
\hline Non-sexual words & 633.79 & 92.76 & 648.44 & 106.72 & 650.97 & 104.82 & .202 & .006 \\
\hline Scrambled sexual words & 658.86 & 128.74 & 685.47 & 106.60 & 669.54 & 143.85 & .272 & .008 \\
\hline Scrambled non-sexual words & 665.14 & 106.16 & 669.86 & 80.04 & 714.52 & 136.81 & 1.515 & .041 \\
\hline Sexually objectifying descriptions of women & 571.42 & 70.99 & 655.56 & 70.46 & 651.39 & 92.12 & $8.852^{* * * *}$ & .200 \\
\hline non-objectifying descriptions & 653.97 & 67.12 & 674.33 & 111.93 & 669.90 & 97.10 & .314 & .009 \\
\hline Scrambled sexually objectifying descriptions & 661.89 & 100.87 & 718.99 & 93.64 & 740.63 & 176.33 & 2.405 & .063 \\
\hline Scrambled non-objectifying descriptions & 669.26 & 104.41 & 705.68 & 98.60 & 734.50 & 137.93 & 1.972 & .053 \\
\hline
\end{tabular}

1. Leisure Suit Larry ${ }^{T M}$

The overall multivariate model is significant, Wilk's Lambda $=.428, \mathrm{~F}(16,128)=4.23, p<.001$

$* * * p<.001$

1999; Lee et al. 2003; Pryor et al. 1993), it is a self-reported tendency rather than an indepently observed behavior. Future research may include other behavioral measures to validate and extend the findings from the present study.

Video game playing requires certain cognitive and muscular skills; a novice player may be likely to have a very different video-gaming experience than would an expert player. Video game playing experience should be considered in future studies. In addition, the interactive nature of video gaming may also result in dramatic differences in terms of video game content as experienced by different game players. For example, some players may be exposed to more sexual content than are others because of the choices they made during game play. This potential differential in game play among participants should be taken into account by future research.

Even after recognizing these limitations, it is nevertheless clear from the findings reported here that there is now strong evidence for negative effects as a result of playing sexually-oriented video games. The present research is
Fig. 1 Participants' estimated harmonic mean lexical decision response latency as a function of word type and game condition.

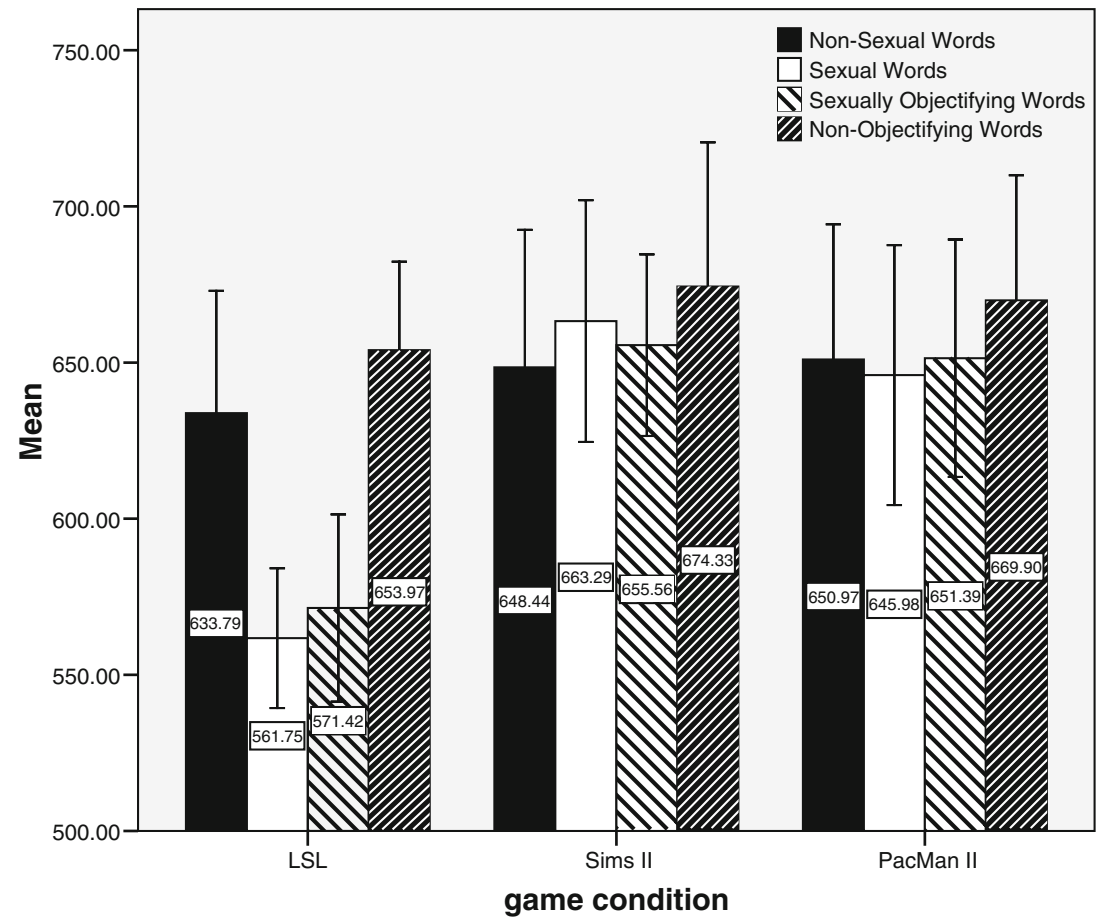

Error Bars: 95\% Cl 
perhaps the first empirical study to systematically examining the effects of these types of video games, and the effects seem to be clear. Overall, the study provides strong empirical evidence that a sexually oriented video game with themes of female "objectification" may prime thoughts related to sex, encourage men to view women as sex objects, and increase the likelihood of self-reported tendencies to behave inappropriately toward women in social situations.

Open Access This article is distributed under the terms of the Creative Commons Attribution Noncommercial License which permits any noncommercial use, distribution, and reproduction in any medium, provided the original author(s) and source are credited.

\section{References}

Anderson, C. A. (2002). Violent video games and aggressive thoughts, feelings, and behaviors. In S. L. Calvert \& R. R. Cocking (Eds.), Children in the digital age: Influences of electronic media on development (pp. 101-116). London: Praeger.

Anderson, J. R., \& Bower, G. H. (1973). Human associative memory. Washington,: V. H. Winston; distributed by the Halsted Press Division of Wiley, New York.

Anderson, C. A., \& Bushman, B. J. (2001). Effects of violent video games on aggressive behavior, aggressive cognition, aggressive affect, physiological arousal, and prosocial behavior: A metaanalytic review of the scientific literature. Psychological Science, $12,353-359$.

Anderson, C. A., \& Bushman, B. J. (2002). Media violence and societal violence. Science, 295, 2377-2378.

Anderson, C. A., \& Dill, K. E. (2000). Video games and aggressive thoughts, feelings, and behavior in the laboratory and in life. Journal of Personality and Social Psychology, 78, 772-790.

Anderson, C. A., Camagey, N. L., Flanagan, M., Benjamin, A. J., Eubanks, J., \& Valentine, J. C. (2004a). Violent video games: Specific effects of violent content on aggressive thoughts and behavior. Advances in Experimental Social Psychology, 36, 199249.

Anderson, C. A., Funk, J. B., \& Griffiths, M. D. (2004b). Contemporary issues in adolescent video game playing: brief overview and introduction to the special issue. Journal of Adolescence, 23, 1-3.

Bandura, A. (1986). Social foundations of thought and action: A social cognitive theory. Englewood Cliffs: Prentice-Hall.

Bandura, A. (2001). Social cognitive theory of mass communication. Media Psychology, 3, 265-299.

Bandura, A. (2002). Social cognitive theory of mass communications. In J. Bryant \& D. Zillman (Eds.), Media effects: Advances in theory and research (2nd ed., pp. 121-153). Hillsdale, NJ: Erlbaum.

Berkowitz, L. (1993). Aggression: Its causes, consequences, and control. New York: McGraw-Hill.

Brathwaite, B. (2007). Sex in video games. Boston, Mass.: Charles River Media.

Brenick, A., Henning, A., Killen, M., O'Connor, A., \& Collins, M. (2007). Social Evaluations of Stereotypic Images in Video Games Unfair, Legitimate, or "Just Entertainment"? Youth \& Society, 38, 295-419.

Buckley, K. E., \& Anderson, C. A. (2006). A theoretical model of the effects and consequences of playing video games. In P. Vorderer \& J. Bryant (Eds.), Playing video games - Motives, responses, and consequences (pp. 363-378). Mahwah: LEA.
Burgess, M. C. R., Stermer, S. P., \& Burgess, S. R. (2007). Sex, lies, and video games: The portrayal of male and female characters on video game covers. Sex Roles, 57, 419-433.

Clifton, A. K., Mcgrath, D., \& Wick, B. (1976). Stereotypes of Woman - Single Category. Sex Roles, 2, 135-148.

Collins, A. M., \& Loftus, E. F. (1975). Spreading Activation Theory of Semantic Processing. Psychological Review, 82, 407-428.

Dall'Ara, E., \& Maass, A. (1999). Studying sexual harassment in the laboratory: Are egalitarian women at high risk? Sex Roles, 41, 681-704.

Deaux, K., Winton, W., Crowley, M., \& Lewis, L. L. (1985). Level of Categorization and Content of Gender Stereotypes. Social Cognition, 3, 145-167.

Dietz, T. L. (1998). An examination of violence and gender role portrayals in video games: Implications for gender socialization and aggressive behavior. Sex Roles, 38, 425-442.

Dill, K. E., \& Thill, K. P. (2007). Video game characters and the socialization of gender roles: Young people's perceptions mirror sexist media depictions. Sex Roles, 57, 851-864.

Dill, K. E., Brown, B. P., \& Collins, M. A. (2008). Effects of exposure to sex-stereotyped video game characters on tolerance of sexual harassment. Journal of Experimental Social Psychology, 44, $1402-1408$.

Donnerstein, E., Linz, D., \& Penrod, S. (1987). The question of pornography: Research findings and policy implications New York. NY: The Free Press.

Fiske, S. T., \& Taylor, S. E. (1991). Social cognition (2nd ed.). New York: McGraw-Hill.

Geer, J. H., \& Bellard, H. S. (1996). Sexual content induced delays in unprimed lexical decisions: Gender and context effects. Archives of Sexual Behavior, 25, 379-395.

Geer, J. H., \& Melton, J. S. (1997). Sexual content-induced delay with double-entendre words. Archives of Sexual Behavior, 26, 295316.

Gerbner, G., Gross, L., Morgan, M., \& Signorielli, N. (1980). The "mainstreaming" of America: Violence profile no.11. Journal of Communication, 30, 10-29.

Gilbert, D. T., \& Hixon, J. G. (1991). The trouble of thinking: Activation and application of stereotypic beliefs. Journal of Personality and Social Psychology, 60, 509-517.

Graham, S., \& Hudley, C. (1994). Attributions of Aggressive and Nonaggressive African-American Male Early Adolescents - a Study of Construct Accessibility. Developmental Psychology, 30, $365-373$.

Gunter, B. (2002). Media sex: what are the issues?. Mahwah: Erlbaum.

Huesmann, L. R. (1998). The role of social information processing and cognitive schema in the acquisition and maintenance of habitual aggressive behavior. In R. G. Geen (Ed.), Human aggression: Theories, research and implications for social policy (pp. 73-109). San Diego: Academic.

Jo, E., \& Berkowitz, L. (1994). A priming effect analysis of media influences: An update. In J. Bryant \& D. Zillmann (Eds.), Media effects. Advances in theory and research (2nd ed., pp. 43-60). Hillsdale: Lawrence Erlbaum Associates.

Kunkel, D., Cope, K. M., Farinola, W. J., Biely, E., Roh, E., \& Donnerstein, E. (1999). Sex on TV: Condent and context. Menlo Park: Kaiser Family Foundation.

Lee, K., Gizzarone, M., \& Ashton, M. C. (2003). Personality and the likelihood to sexually harass. Sex Roles, 49, 59-69.

Linz, D., \& Malamuth, N. M. (1993). Pornography. Newbury Park: Sage Publications.

Malamuth, N., Linz, D., \& Yao, M. Z. (2005). The Internet and aggression: Motivation, disinhibitory and opportunity aspects. In Y. Amichai-Hamburger (Ed.), The social net: Human 
behavior in cyberspace (pp. 163-191). New York: Oxford University Press.

Manis, M., Paskewitz, J., \& Cotler, S. (1986). Stereotypes and Social Judgment. Journal of Personality and Social Psychology, 50, 461-473.

McKenzie-Mohr, D., \& Zanna, M. P. (1990). Treating women as sexual objects: Look to the (gender schematic) male who has viewed pornography. Personality and Social Psychology Bulletin, 16, 296-308.

Meyer, D. E., \& Schvaneveldt, R. W. (1971). Facilitation in recognizing pairs of words: Evidence of a dependence between retrieval operations. Journal of Experimental Psychology, 90, 227-234.

Meyer, D. E., \& Schvaneveldt, R. W. (1976). Meaning, memory structure, and mental processes. Science, 192, 27-33.

Miller, M. K., \& Summers, A. (2007). Gender differences in video game characters' roles, appearances, and attire as portrayed in video game magazines. Sex Roles, 57, 733-742.

Mulac, A., Jansma, L. L., \& Linz, D. G. (2002). Men's behavior toward women after viewing sexually-explicit films: Degradation makes a difference. Communication Monographs, 69, 311-328.

Potter, W. J. (1999). On media violence. Thousand Oaks: Sage Publications.

Provenzo, E. F. (1991). Video kids: Making sense of Nintendo. Cambridge: Harvard University Press.

Pryor, J. B. (1987). Sexual Harassment Proclivities in Men. Sex Roles, $17,269-290$

Pryor, J. B., \& Meyers, A. B. (2000). Men who sexually harass women. In L. B. Schlesinger (Ed.), Serial offenders: Current thought, recent findings, unusual syndromes (pp. 207-228). Boca Raton: CRC Press.

Pryor, J. B., LaVite, C., \& Stoller, L. (1993). A social psychological analysis of sexual harassment: The person/situation interaction. Journal of Vocational Behavior, 42, 68-83.

Ratcliff, R. (1993). Methods for Dealing with Reaction-Time Outliers. Psychological Bulletin, 114, 510-532.

Ray, S. G. (2004). Gender inclusive game design: Expanding the market Hingham. MA: Charles River Media.

Roskos-Ewoldsen, D. R., Roskos-Ewoldsen, B., \& Dillman Carpentier, F. R. (2002). Media priming: A synthesis. In J. Bryant \& D. Zillmann (Eds.), Media effects: Advances in theory and research (2nd ed., pp. 97-120). Mahwah: Lawrence Erlbaum Associates.
Rudman, L. A., \& Borgida, E. (1995). The afterglow of construct accessibility: The behavioral consequences of priming men to view women as sexual objects. Journal of Experimental Social Psychology, 31, 493-517.

Scharrer, E. (2005). Hypermasculinity, aggression, and television violence: An experiment. Media Psychology, 7, 353-376.

Sheff, D. (1993). Game over: how Nintendo zapped an American industry, captured your dollars, and enslaved your children. New York: Random House.

Sherry, J. L. (2001). The effects of violent video games on aggression: A meta-analysis. Human Communication Research, 27, 409-431.

Shrum, L. I. (2002). Media consumption and perceptions of social reality: Effects and underlying processes. In J. Bryant \& D. Zillmann (Eds.), Media effects. Advances in theory and research (2nd ed., pp. 69-95). Mahwah: Lawrence Erlbaum Associates.

Spiering, M., Everaerd, W., \& Elzinga, B. (2002). Conscious processing of sexual information: Interference caused by sexual primes. Archives of Sexual Behavior, 31, 159-164.

Terdiman, D. (2005). Adult-oriented video games prospering. CNET News.com. Retrieved from http://news.cnet.com/Adult-orientedvideo-games-prospering/2100-1043_3-5886552.html

Ward, L. M. (2002). Does television exposure affect emerging adults' attitudes and assumptions about sexual relationships? Correlational and experimental confirmation. Journal of Youth and Adolescence, 31, 1-15.

Wicks, R. H. (1992). Schema theory and measurement in mass communication research: Theoretical and methodological issues in news information processing. In S. A. Deetz (Ed.), Communiation Yearbook 15 (pp. 115-145). Newbury Park: Sage.

Zarate, M. A., \& Smith, E. R. (1990). Person Categorization and Stereotyping. Social Cognition, 8, 161-185.

Zillmann, D., \& Bryant, J. (1982). Pornography, sexual callouseness, and the trivalization of rape. Journal of Communication, 32, 10 21.

Zillmann, D., \& Sapolsky, B. S. (1977). What mediates effect of mild erotica on annoyance and hostile behavior in males. Journal of Personality and Social Psychology, 35, 587-596.

Zillmann, D., Bryant, J., Comisky, P. W., \& Medoff, N. J. (1981). Excitation and hedonic valence in the effect of erotica on motivated intermale aggression. European Journal of Social Psychology, 11, 233-252. 